\title{
OVERVIEW OF RECRUITMENT AND SELECTION PROCESS IN HRM
}

\author{
Dr. C K GOMATHY, Mr. A.L.S. Ramaseshacharyulu, Mr. Ch. Sai Sarath, Mr. Alapati Sai Sreekanth
}

Sri Chandrasekharendra Saraswathi Viswa Mahavidyalaya , Kanchipuram

\begin{abstract}
In any kind of organization, recruitment and selection processes are considered useful, because they help in finding the most suitable candidates for the jobs. Recruitment and selection are important operations in human resource management, designed to make best use of employee strength in order to meet the strategic goals and objectives of the employers and of the organization as a whole. It is a process of screening, sourcing, shortlisting, and selecting the right candidates for the vacant positions. The employers put into practice recruitment strategies and methods that would be the most beneficial to achieve organizational goals and objectives. The main purpose of this research paper is to understand recruitment and selection procedures. The main areas that have been taken into account include, significance of recruitment and selection, principles of recruitment and selection, factors affecting recruitment and selection, posting vacancies, recruitment and selection process, types of recruitment and types of interviews. Selection is the process of picking or choosing the right seeker, who's most suitable for the job. It's the process of canvassing the campaigners and assessing their rates, which are necessary for a specific job and also selection of the campaigners is made for the right positions. The selection of right campaigners for the right positions will help the association to achieve its asked pretensions and objects. When selection of the workers takes place, it's vital to insure that they retain the asked qualifications, chops and capacities that are needed to perform the job duties in a well-organized manner.
\end{abstract}

Key Words: Recruitment, Selection, Candidates, Organizations, Jobs, Factors, Interview.

\section{INTRODUCTION:}

Reclamation is the process of relating, screening, shortlisting and hiring of the implicit mortal coffers for the purpose of filling up the positions within the associations. It's the central function of mortal resource operation. Reclamation is the process of opting the right person, for the right position at the right time. The educational qualifications, experience, capacities and chops of the individualities need to be taken into consideration when reclamation takes place. It's the process of attracting, opting and appointing implicit campaigners to meet the requirements and conditions of the associations. Reclamation takes place internally, i.e., within the association and externally, i.e., from the operation of external sources. Internal factors include, the size of the association, retaining policy, image of association and image of job.

Reclamation is called a positive process with its approach of attracting as numerous campaigners as possible for the vacant positions. It's the process of relating and making implicit campaigners to apply for the jobs. On the other hand, selection is called a negative process with the elimination of numerous campaigners as possible. There are multitudinous individualities, who apply for the jobs, but selection is made only of those individualities, who are good and complete. Selection is important, the reason being, hiring of good coffers can help in adding the overall performance of the association. Both the processes of reclamation and selection are considered important for the effective functioning of the associations and they take place contemporaneously. They're imperative for growth and development of the association.

\section{SIGNIFICANCE OF RECRUITMENT AND SELECTION:}

The reclamation and selection of the individualities within the associations affect from a thorough and a methodical process. The workers need to retain complete knowledge of the strategies and styles that are needed to get enforced for reclamation and selection. Legislation and good practice and the range of reclamation sources and selection styles as well 
as enjoying the chops and capacities in canvassing and assessing implicit workers punctuate the significance of reclamation and selection. The areas that punctuate the significance of reclamation and selection have been stated as follows:

When job vacuities arise within the associations, also the employers give due consideration to the reclamation and selection processes. These processes enable the employers to identify and assay the positions that are needed to get filled in order to achieve the asked pretensions and objects. Vacant positions within the associations signify the lack of mortal coffers and these are regarded as walls within the course of perpetration of tasks and in the achievement of pretensions and objects. Therefore, whether it may take place on an immediate base or may be a time-consuming process, significance of these processes is honoured during the time of job vacuities.

Coffers are considered as the most important asset of any association, hence, hiring the help with applicable chops and capacities is important. The patterns of reclamation and selection differ from one company to another. When machines, outfit and bias are made use of to enhance productivity, also it's the mortal coffers that operate them. The machines, bias and other outfit are made use of in an effective way, when they're put into operation by professed and complete help. It's vital that individualities should retain complete knowledge regarding how to make use of machines and enhance productivity. In some cases, this job may be manageable, whereas in others it may be tedious and demanding. Thus, reclamation and selection are considered as important aspects in any association and should be made of applicable help.

\section{PRINCIPLES OF RECRUITMENT AND SELECTION:}

The principles of recruitment and selection have been stated as follows:

The first point to identify about reclamation is that it's a process with a number of crucial stages, all of which work in cooperation to ameliorate one's chances of chancing the stylish campaigners available for any advertised position. The campaigners are needed to go through colorful stages and they're given certain tasks or go through colorful rounds of interviews, which they've to negotiate in order to get named. In some cases, final round of interviews, include only two people, one is named and the other bone gets rejected.

It is worth giving indications that in terms of leading, guiding and managing employees, if one is not recruiting the best people available, then it is always going to be challenging to manage them on daily basis. Another general rule is, when seeking to fill any job vacancy, one should always consider the internal candidates that could be encouraged to the available post and then recruit externally for the junior position.

Too often senior managers pay less attention to the recruitment process and only become actively involved when a senior post is being filled, or at the end of the process for the final interview. This is an error and one should be concerned with the eminence and appropriateness of every employee, who joins the business.

It is often assumed that interviewing is something that any experienced manager can carry out. It involves open ended as well as close ended questions. Interviews can be conducted by anybody, but it is important that individuals can do it well, if they are appropriately trained and possess effective communication skills. It is not worthwhile to conduct interviews without acquiring proper training.

There are many legal issues that are associated with the recruitment process and it is necessary for all the individuals to familiarise oneself with the relevant legislation. It is vital for the members of the organization to become familiar with the policies and procedures that are required in the recruitment and selection processes.

\section{FACTORS AFFECTING RECRUITMENT AND SELECTION:}


The factors affecting recruitment and selection are organized into the internal and the external categories. The internal factors have been stated as follows:

Size of the Organization - The size of the organization is one of the most important factors affecting the recruitment process. To develop business, recruitment planning is mandatory for hiring more resources, which will be crucial in the management of future operations.

Image of Jobs - Just like the image of the organization, the image of jobs contributes a critical role in the recruitment and selection processes. Jobs having a positive image in terms of better remuneration, promotions, recognition, and amiable working environment with career development opportunities are considered as the characteristics to arouse interest and enthusiasm within qualified candidates.

The external factors have been stated as follows:

Unemployment rate - If the unemployment rate is high in a specific area, hiring of human resources will be simple and manageable, as there will be an increase in the number of applicants. For various job positions in all types of organizations, large number of applications are received. In contrast, if the unemployment rate is low, then recruiting tends to be difficult due to lesser number of resources.

Labour laws - Labour laws reflect the social and political environment of the market, which are created by the central and the state governments. These laws dictate the compensation, working environment, safety and health regulations, and the job duties of the workforce, for different types of employments. As the governments undergo transformations, there are transformations that come about in the labour laws.

Legal considerations - Job reservations for different castes such as Scheduled Tribes, Scheduled Castes, and Other Backward Classes are the best examples of legal considerations. These considerations, passed by government, will have a positive or negative impact on the recruitment policies of the organizations.

Equal Opportunity - When recruitment and selection of the employees take place, then it is vital to take into consideration, equal employment opportunities for the individuals. Equal opportunity results when all the applicants are treated on an equal basis and consistently at every stage of recruitment.

\section{POSTING VACANCIES:}

Job posting refers to the practice of publicising and displaying advertisements of an open job to the employees. In most cases, internet, newspapers, notices and bulletin boards are the areas where job postings are found. These include, listing of the attributes, such as, designation, criteria of knowledge, qualifications, skills and experience. In some cases, they also specify the salary package. The purpose of posting vacancies is to bring to the attention of the interested persons, they may be internal or external to the organisation and the jobs that are to be filled. Before posting vacancies, important areas that need to be taken into consideration by the employers include: (Richardson, n.d.).

Whether the retention of the job is done in the present form with the title, remuneration or status or whether any changes are required to be brought about.

\section{DETAILED RECRUITMENT AND SELECTION PROCESS:}

It is important that the job announcements should be made available to all the employees. Satisfactory job postings can ensure that minority workers and other individuals belonging to disadvantaged groups and economically weaker sections of the society are aware of the opportunities within the organization. The weakness to the job positing is employee pessimism that occurs when jobs are posted as open, but in reality, the organization has already selected a 
strong internal candidate. Such practices generate antipathy and disbelief among employees, when they believe the job posting is just a formality with less real opportunity for advancement (Gus Dorf, 2008).

The elements in the recruitment and selection processes have imperative contributions to make in helping find most suitable candidates for the given posts. The elements have been stated as follows:

Job Vacancy - The first step is when vacancy arises within the organization. One should be aware of the vacant positions and by when they should get filled with capable employees. Job vacancy enables the individuals to determine the factors, such as, redesigning, or initiating part time employment opportunities for the individuals. In some cases, vacant positions may get filled with qualified candidates rapidly, whereas in others, it may be a time-consuming process. One should implement measures to reduce the risks associated with recruitment. The existing employees should see that there is a potential career path within the organization, which may motivate them to stay longer.

Job Analysis - Two main factors need to be taken into consideration regarding job analysis. First is expectation of the employers from their employees, within the organization, the employers have certain expectations from their employees regarding performance of job duties, and they expect them to inculcate the traits of regularity, diligence, resourcefulness, conscientiousness and creativity. The other areas that need to be taken into consideration are the characteristics of the job. These include, training, work experience, skills and knowledge, physical attributes, personality traits, communication skills and personal circumstances. Development and utilization of well-structured questions based on the profile of the employees will help in getting the better insight of the true personality of the candidate.

Attracting Candidates - In attracting candidates for the jobs, there are two important sources that need to be taken into consideration, internal recruitment and external recruitment. In the case of internal recruitment, the following advantages are, it reduces recruitment costs, internal employees are already familiar with all the aspects of the organization, its goals, objectives etc. It can act as a motivating factor for others in the business by displaying that it is possible to acquire promotional opportunities and the employers are already familiar with the person, within the organization. Sources of external recruitment includes, websites, advertisements in newspapers, journals, magazines, recruitment agencies, consultants, employment fairs, and seminars.

Screening Candidates - The purpose of the screening process is to narrow down the field, so that one is able to spend more time with the candidates for formal interviews. Large numbers of applications are received for the positions, and all the applicants are not called for the interviews, hence, it is vital for the employers to screen the candidates to select the most suitable ones for the interviews. In the number of applications received, screening is done on the basis of factors such as, educational qualifications, experience, skills, and so forth. When this process has been effectively implemented, only then the screening process takes place. After the screening process is implemented in an adequate manner, then interviews are organized for the candidates.

Interviewing Candidates - The important aspects that need to be taken into account for interviewing candidates include, ensuring that proper notice is given regarding the date and time of the interview, ensuring that the candidates are aware that they should reach the premises on time, ensuring that they are clear where to go and whom they should contact on arrival and ensuring that they are aware of the documents that need to be brought along in the interview. These aspects contribute in preparing the candidates on the complete basis for the interview. The employers or the interviewers need to review the resume and all the job applications before interviewing the candidates. It is vital to implement time management skills for the interview processes, so that they can be completed on time.

Selecting and Appointing Candidates - The methods of selecting and appointing candidates are different in various organizations. The procedures generally include the steps, such as, the selection of the candidate, verbal communication of his or her appointment, medical completed if appropriate, sending of appointment letters and signing the contract. Selecting and appointing candidates depend upon the urgency of getting the vacancy filled. When job vacancies are to be urgently filled, then selecting and appointing of candidates may take place immediately after the interviews. In some 
organizations, candidates are appointed on an immediate basis, after their selection and other formalities, such as giving appointment letters or signing the contract.

Induction and Training - Induction is the process of receiving and welcoming of the employees, after they have been selected and providing them the required training needed to settle down adequately. Induction has three aims, to smooth the early stages, when everything is likely to be extraordinary and unfamiliar to the new employees. To establish a positive attitude of the organization within the mind-sets of the employees, so that they are likely to stay for a long term and to obtain effective output from new employees in short period of time. Training is referred to making use of methods and strategies to enhance the awareness, knowledge and information among the employees. Various training methods include, role plays, vestibule training, field visits, and lectures. The employees should receive on the job and off the job training to generate information regarding history, personnel, goals and performance of job duties. The main purpose of training is to balance the needs and requirements of the organizations and human resources.

Employee Evaluation - Monitoring the performance of the employees is an essential aspect within the organization. It is necessary to evaluate the employees from time to time in order to monitor enhancement of productivity and their performance. The methods of employee evaluation help in identifying the limitations and the measures that are required to get implemented to improve them. Monitoring the performance of the employees is stated as an on-going activity and new employees can be trained in a better way to enhance productivity. The evaluation process can tell whether the recruitment process is working efficiently or are there any changes and transformations that need to be brought about. The main purpose is to ensure that the quality of the employees get enhanced that are recruited within the organizations. This is imperative to improve employee productivity and to achieve the organizational goals and objectives.

\section{CONCLUSION:}

Human resources are stated to be an integral part of any organization. The jobs, functions, tasks and operations can be adequately performed by proficient and skilled personnel. Therefore, within the organizational structure, it is vital to implement effective recruitment strategies and selection processes. When the members of the organization are aware of proper recruitment and selection processes, then they are able to make selection of human resources in an appropriate manner. There are numerous job duties and functions within the organization and performance of all kinds of tasks and operations require skills and abilities, which can be honed by making provision of adequate training to the personnel.

The individuals hired may be experienced and knowledgeable, but they do experience changes and transformations within the organizations regarding various aspects, such as, the working environmental conditions, performance of job duties, attitudes and behavioural traits of the employers, methods to enhance productivity, utilization of innovative techniques and methods and so forth. When the employees are selected, it is important that they should be loyal and dedicated towards the organizations. They should be committed towards the performance of job duties and possess the traits of resourcefulness, diligence, and conscientiousness. Finally, it can be stated that organizations are required to put into practice recruitment and selection processes with accuracy, precision and truthfulness.

\section{REFERENCES:}

[1] C.K.Gomathy.(2010),"Cloud Computing: Business Management for Effective Service Oriented Architecture" International Journal of Power Control Signal and Computation (IJPCSC), Volume 1, Issue IV, Oct - Dec 2010, P.No:22-27, ISSN: 0976-268X .

[2] Dr.C K Gomathy, Article: A Study on the recent Advancements in Online Surveying, International Journal of Emerging technologies and Innovative Research ( JETIR ) Volume 5 | Issue 11 | ISSN : 2349-5162, P.No:327-331, Nov-2018 
[3] Dr.C.K.Gomathy,C K Hemalatha, Article: A Study On Employee Safety And Health Management International Research Journal Of Engineering And Technology (Irjet)- Volume: 08 Issue: 04 | Apr 2021

[4] Dr.C K Gomathy, Article: A Study on the Effect of Digital Literacy and information Management, IAETSD Journal For Advanced Research In Applied Sciences, Volume 7 Issue 3, P.No-51-57, ISSN NO: 2279-543X,Mar/2018

[5] Dr.C K Gomathy, Article: An Effective Innovation Technology In Enhancing Teaching And Learning Of Knowledge Using Ict Methods, International Journal Of Contemporary Research In Computer Science And Technology (Ijcrcst) E-Issn: 2395-5325 Volume3, Issue 4,P.No-10-13, April '2017

[6] Dr.C K Gomathy, Article: Supply chain-Impact of importance and Technology in Software Release Management, International Journal of Scientific Research in Computer Science Engineering and Information Technology ( IJSRCSEIT ) Volume 3 | Issue 6 | ISSN : 2456-3307, P.No:1-4, July-2018.

[7] 2. Klug, D. (2017). Recruitment and Selection Handbook for University Staff Positions. Arizona State University.

\section{AUTHORS:}

1.

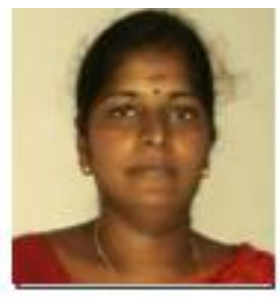

Dr.C.K. Gomathy is Assistant Professor in Computer Science and Engineering at Sri Chandrasekharendra Saraswathi Viswa Mahavidyalaya, Enathur, Kanchipuram, India.

2

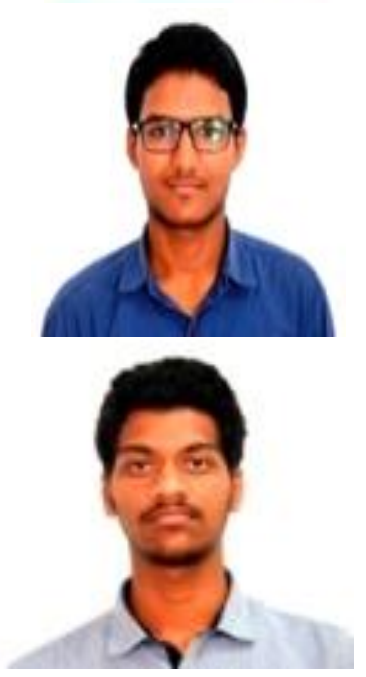

Mr. A.L.S. Ramaseshacharyulu, 11189A006, Student, B.E. Computer Science and Engineering at Sri Chandrasekharendra Saraswathi Viswa Mahavidyalaya, Enathur, Kanchipuram, India.

Mr. Chodisetty Sai Sarath, 11189A054, Student, B.E. Computer Science and Engineering at Sri Chandrasekharendra Saraswathi Viswa Mahavidyalaya, Enathur, Kanchipuram, India.

4.

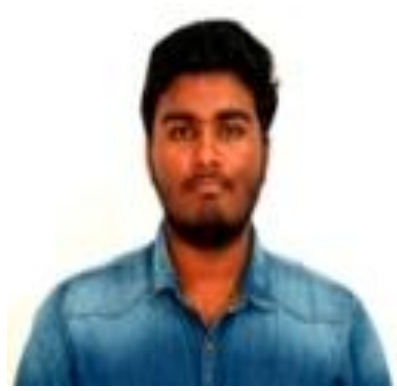

Mr. Alapati Sai Sreekanth, 11189A011, Student, B.E. Computer Science and Engineering at Sri Chandrasekharendra Saraswathi Viswa Mahavidyalaya, Enathur, Kanchipuram, India. 